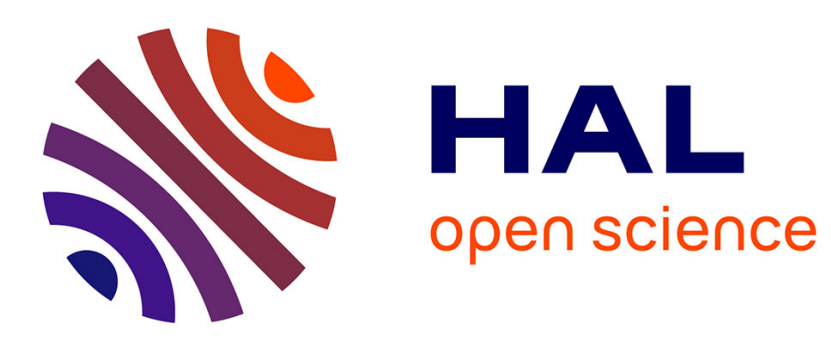

\title{
Electroactive self-assembled monolayers: A versatile function to fit symmetric voltammetric peak
}

Olivier Alévêque, Eric Levillain

\section{To cite this version:}

Olivier Alévêque, Eric Levillain. Electroactive self-assembled monolayers: A versatile function to fit symmetric voltammetric peak. Electrochemistry Communications, 2015, 51, pp.137-143. 10.1016/j.elecom.2014.12.023 . hal-01153473

\section{HAL Id: hal-01153473 https://hal.science/hal-01153473}

Submitted on 5 Aug 2020

HAL is a multi-disciplinary open access archive for the deposit and dissemination of scientific research documents, whether they are published or not. The documents may come from teaching and research institutions in France or abroad, or from public or private research centers.
L'archive ouverte pluridisciplinaire HAL, est destinée au dépôt et à la diffusion de documents scientifiques de niveau recherche, publiés ou non, émanant des établissements d'enseignement et de recherche français ou étrangers, des laboratoires publics ou privés. 
Electroactive self-assembled monolayers: A versatile function to fit symmetric voltammetric peak.

Olivier Alévêque and Eric Levillain*

Université d'Angers, CNRS UMR 6200, Laboratoire MOLTECH-Anjou, 2 bd Lavoisier, 49045 ANGERS cedex, France.

* Corresponding authors: Tel.: (+33)241735090; Fax: (+33)241735405

E-mail address: eric.levillain@univ-angers.fr (Eric Levillain)

\begin{tabular}{l|l}
\hline ARTICLE INFO & ABSTRACT \\
\hline $\begin{array}{l}\text { Keywords: } \\
\text { Self-assembled monolayers }\end{array}$ & $\begin{array}{l}\text { We propose a versatile function to fit adsorption voltammetric peak in order to extract the } \\
\text { characteristic parameters as the full width at half maximum, the peak potential, the peak } \\
\text { Cyclic voltammetry }\end{array}$ \\
$\begin{array}{l}\text { current and the surface coverage. Based on the generalized Gaussian function and } \\
\text { supported by generalized lateral interactions model, this method has been tested on different } \\
\text { Generalized Gaussian function }\end{array}$ & $\begin{array}{l}\text { electroactive self-assembled monolayers (i.e. ferrocene, bithiophene, tetrathiafulvalene and } \\
\text { radical aminoxyl units). }\end{array}$ \\
\hline
\end{tabular}

\section{Introduction}

Current-voltage behaviours of electroactive self-assembled monolayers (SAMs) can be simple or complex with sharp, normal or broad shapes [1,2] and one of the major obstacles facing those who wish to analyse raw data is how to extract characteristic parameters $\left(E_{p}, i_{p}\right.$, and FWHM) from experimental cyclic voltamograms (CVs). The only alternative to CV peak analysis is often to use the graphical powerful analysis tools of the turnkey instrument control software (i.e. EC-Lab from Biologic, VersaStudio Software from Princeton Applied Research, etc.).

Previous works [3-7] have proposed to fit unusual CV peaks via usual or unusual functions such as Gaussian, Lorentzian, or Extreme function but these calculations were either very intricate or not based on a theoretical support.

Herein, we propose a versatile method to fit experimental peak in order to extract characteristic parameters $\left(E_{p}, i_{p}, F W H M\right.$ and $\Gamma$ ) of cyclic voltamograms (CVs), especially for non-ideal voltamograms where no algebraic equation does exist. This approach is compared to the extended Laviron's interactions model [8, 9] and then to electrochemical data obtained from several electroactive SAMs. 


\section{Generalized lateral interactions model}

In a previous work $[8,9]$, we have presented a theoretical study to complete the lateral interaction model proposed by E. Laviron [10], by extending this initial model to non-random distributions of electroactive sites adsorbed on surface. This model enables current-voltage behaviours to be simulated and allows extracting characteristics parameters of cyclic voltamograms (CVs) obtained from any surface distribution of electroactive SAM.

To summarize, the generalized lateral interactions model can be defined according to the main following hypotheses [9-12]:

- The electroactive centers are distributed on substrate with a unimodal statistical distribution of electroactive neighbours. A parameter $\phi(\theta)$, between 0 and 1 , defined for a normalized surface coverage $\theta$, quantifies the segregation level of the electroactive centers. For a randomly distributed SAM, $\phi(\theta)=\theta$, and when a segregation exists on the surface, $\phi(\theta)>\theta$.

- The sum of normalized surface coverage $\theta_{0}$ and $\theta_{R}$ of oxidized $(O)$ and reduced $(R)$ species is constant and equal to $\theta$,

- The surface occupied by one molecule of $O$ is equal to the surface occupied by one molecule of $R$,

- The electrochemical rate constant $\mathrm{k}_{\mathrm{s}}$ is independent of the coverage,

- $a_{O O}, a_{R R}$ and $a_{O R}$ are the interaction constants between molecules of $O$, molecules of $R$ and molecules of $\mathrm{O}$ and $\mathrm{R}$, respectively. $\mathrm{a}_{\mathrm{ij}}$ is positive for an attraction and negative for a repulsion.

For a full reversible reaction $\left(\mathrm{k}_{\mathrm{s}} \rightarrow \infty\right), \mathrm{CVs}$ are reversible, and the characteristic parameters as full width at half maximum $(F W H M)$, peak potential $\left(E_{p}\right)$ and peak current $\left.\left(i_{p}\right)\right)$ are defined as:

$$
\mathrm{E}_{\mathrm{p}}(\phi(\theta))=\mathrm{E}_{0}^{\prime}+\frac{\mathrm{RT}}{\mathrm{nF}} \mathrm{S} \phi(\theta)
$$

$\mathrm{FWHM}(\phi(\theta))=\frac{2 \mathrm{RT}}{\mathrm{nF}}\left[\ln \left[\frac{1+\sqrt{\frac{2-\mathrm{G} \phi(\theta)}{4-\mathrm{G} \phi(\theta)}}}{1-\sqrt{\frac{2-\mathrm{G} \phi(\theta)}{4-\mathrm{G} \phi(\theta)}}}\right)-\mathrm{G} \sqrt{\frac{2-\mathrm{G} \phi(\theta)}{4-\mathrm{G} \phi(\theta)}} \phi(\theta)\right] \stackrel{|\mathrm{G} \phi(\theta)<1|}{\approx} \frac{\mathrm{RT}}{\mathrm{nF}}\left(2 \ln (2 \sqrt{2}+3)-\frac{3 \sqrt{2}}{2} \mathrm{G} \phi(\theta)\right)$

$\mathrm{i}_{\mathrm{p}}(\phi(\theta))=\frac{\mathrm{n}^{2} \mathrm{~F}^{2} \mathrm{vA} \Gamma_{\max }}{\mathrm{RT}} \frac{\theta}{2(2-\mathrm{G} \phi(\theta))}$

with, $G=a_{O O}+a_{R R}-2 a_{O R}$ et $S=a_{R R}-a_{O O} \quad(|G|$ and $|S| \leq 2)$ 
$G$ and $S$, play a primordial role and can be defined as "interaction" parameters of $O$ and $R$, respectively. The parameter $\mathrm{G}$ defines the shape of the peak (FWHM) and the peak intensity $\left(\mathrm{i}_{\mathrm{p}}\right)$ and the parameter $\mathrm{S}$, the peak potential $\left(E_{p}\right)$ as a function of $\theta$.

\section{The Generalized Gaussian Function (GG Function)}

Known as the exponential power distribution, or the generalized Gaussian distribution, this distribution is a parametric family of symmetric distributions. It includes all normal and Laplace distributions, and in some limiting cases it includes all continuous uniform distributions on bounded intervals of the real line.

Applied to a CV peak, the generalized Gaussian function can be expressed as:

$$
i(E, a, b, c)=\frac{a}{2 \cdot b \cdot \Gamma(1+1 / c)} e^{-\left(\frac{\left|E-E_{p}\right|}{b}\right)^{c}} \text { with }\left\{\begin{array}{l}
E_{p}, \text { peak potential } \\
\Gamma, \text { the Gamma function }
\end{array}\right.
$$

and the characteristic parameters are defined as:

$$
\begin{aligned}
& F W H M=2 \cdot b \cdot[\ln (2)]^{\frac{1}{c}} \\
& i_{p}=\frac{a}{2 \cdot b \cdot \Gamma(1+1 / c)} \\
& \Gamma_{S G}=\frac{a}{n F A v} \text { with }\left\{\begin{array}{l}
A, \text { the electrode area } \\
v, \text { the scan rate }
\end{array}\right.
\end{aligned}
$$

In order to avoid confusion with the Gamma function $(\Gamma)$, the symbol of the surface coverage is named $\Gamma_{\text {SG. }}$. (i.e. $\left.\Gamma_{\mathrm{SG}}=\Gamma_{\max } \cdot \theta\right)$.

\section{Discussions}

\subsection{Starting from an ideal case}

Let us take the ideal but simplistic case (i.e. Langmuir model and $G=S=0$ ): all adsorption sites are equivalent and there is no interaction between immobilized electroactive centers, leading to a CV shape independent of the surface coverage. In this particular case, an algebraic equation was formulated by Laviron [11] to describe the CVs, and allows us to verify the robustness of fits generally used. 


$$
f(E)=\frac{n^{2} F^{2} A v \Gamma_{\max } \theta}{R T} \frac{\mathrm{e}^{\left(\frac{n F}{R T}\left(E-E_{0}\right)\right)}}{\left(1+\mathrm{e}^{\left(\frac{n F}{R T}\left(E-E_{0}\right)\right)}\right)^{2}}
$$

Gaussian, Lorentzian and Extreme functions do not match the ideal case (Figure 1A and 1B) and astonishingly, some previous work have used these empirical functions to estimation $E_{p}, i_{p}, F W H M$ and $\Gamma_{S G}$ parameters.

Conversely, the GG function provides a relevant fit (Figure 1C). Nonetheless it is important to note that the GG function requires 4 parameters and not 3, as Gaussian and Lorentzian functions, and that multiple minima can occur during the refinement because $b$ and $c$ seem to be dependent variables.

\subsection{Dependence of $b$ and $c$}

The dependence of $\mathrm{b}$ and $\mathrm{c}$ can be solved by finding a correlation between the generalized lateral interactions model and the GG function. Mathematically, equations 2 and 5 lead to:

$$
\mathrm{FWHM} \stackrel{|\mathrm{G} . \phi(\theta)|<1}{=} \frac{\mathrm{RT}}{\mathrm{nF}}\left(2 \ln (2 \sqrt{2}+3)-\frac{3 \sqrt{2}}{2} \mathrm{G} \cdot \phi(\theta)\right)=2 \cdot \mathrm{b} \cdot[\ln (2)]^{\frac{1}{\mathrm{c}}}
$$

and equations 3 and 6 to:

$$
i_{p}=\frac{n^{2} F^{2} v A \Gamma_{\mathrm{m}}}{R T} \frac{\theta}{2(2-G \phi(\theta))}=\frac{a}{2 \cdot b \cdot \Gamma(1+1 / c)}
$$

From the equations 9 and 10 , the parameter $\mathrm{b}$ can be expressed as a function of the parameter $\mathrm{c}$ via a simple relation and, remarkably, independent of G. $\phi(\theta)$ :

$$
b=2 \frac{R T}{n F}\left[\frac{3 \sqrt{2}-2 \ln (2 \sqrt{2}+3)}{3 \sqrt{2} \cdot \Gamma(1+1 / c)-4 \cdot[\ln (2)]^{\frac{1}{c}}}\right]
$$

From the equations 9 and 10, an relationship between $\mathrm{c}$ and $\mathrm{G} . \phi(\theta)$ allows to estimate the boundary values $(|\mathrm{G} . \phi(\theta)|<1)$ of $\mathrm{c}$, according to:

$$
(4-2 G) \cdot[\ln (2)]^{\frac{1}{c}}=\left(2 \ln (2 \sqrt{2}+3)-\frac{3 \sqrt{2}}{2} G \phi(\theta)\right) \cdot \Gamma(1+1 / c)
$$

A numerical solving of the equation 12 shows that the parameter $\mathrm{c}$ is strictly greater than 1 (i.e. close to $1.0166,1.5691$ and 2.0182 for $\mathrm{G} . \phi(\theta)$ equal to $+1,0$ and -1 , respectively). 
To close this section, the GG function supported by lateral interactions model must be expressed as:

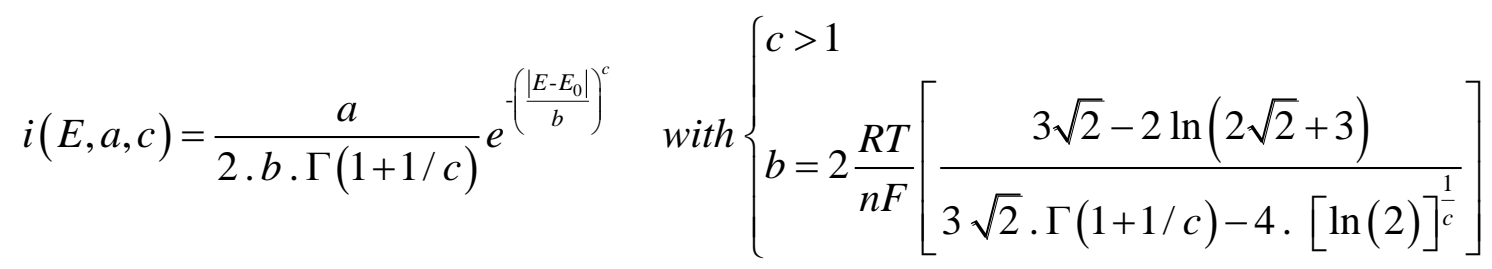

Note that, for $3>c>1$, b varies quasi linearly with $c$ and can approximated to:

$$
b \stackrel{3>c>1}{\approx} \frac{R T}{n F}\left(\sqrt{2 \pi} \cdot c-\frac{5}{3}\right)
$$

\subsection{GG function vs. generalized lateral interactions model}

First of all, we simulated some CVs from generalized lateral interactions model with relevant $G$ and $S$ parameters in extreme cases (i.e. $G=-S=+1$ and $G=-S=-1$ ) with $\phi(\theta)>\theta$ (Figure 2A and 2B). Then, each CV shape was fitted with GG function (i.e. 3 and 4 unknown parameters) (Figure 2C and 2D). Then, the characteristic parameters $\left(E_{p}, i_{p}, F W H M\right.$ and $\left.\Gamma_{S G}\right)$ of each CV were extracted and, finally, plotted against $\theta$ (Figure 2E and 2F) for comparison to expected values from generalized Laviron model.

The right agreement between mathematical shapes and modelled CV peaks in two extreme cases of phase segregation provides evidence of the versatility of GG function, for both 3 and 4 unknown parameters. The characteristic parameters are consistent with Laviron's model in a wide range of surface coverage and we can notice that the values of FWHM for a peak fit with 3 parameters are less likely to agree with the Laviron's model. This slight difference is due to the relationship between $b$ and $c$ (equation 11).

\subsection{GG function vs. experimental CVs}

It is well-known that the baseline can disturb the extraction of unknown parameters by peak fitting from experimental data and, herein, a monotonic polynomial function (i.e. $g(x)= \pm \sum_{i=0}^{n}\left|a_{i} \cdot x^{i}\right|$ ) was selected for the baseline approximation in order to circumvent this problem.

\subsubsection{Different electroactive SAMs}


Figure 3 shows that GG function peak fitting is successfully extracting $E_{p}, i_{p}, F W H M$ and $\Gamma_{S G}$ of experimental electroactive SAMs ((i.e. ferrocene [13], bithiophene [14], tetrathiafulvalene [15] and radical aminoxyl [10] units ), equally to one CV peak as to two. In the latter case, the two CV peaks were fitted with two GG functions of the same area (i.e. $a_{1}=a_{2}-$ Figure $3 C$ and $3 D$ ).

As expected, the usual slight dissymmetry of the CV peak of ferrocene SAM leads to a correct but no more result of the peak fitting (Figure 3B).

\subsubsection{Mixed TEMPO SAMs}

The robustness of the GG function peak fitting was tested through mixed SAMs (Figure 4). We opted for mixed Tempo:decanethiol SAMs, prepared by successive dilutions [8]. Such conditions lead to the random distributed (i.e. $\phi(\theta)=\theta$ ) electroactive centers on Au substrate and predict a linear dependence of peak potential (see equation 1) and FWHM (see equation 2) with the surface coverage [8].

A right agreement between GG peak and experiment shape was observed in the full range of surface coverage (Figure $4 A)$. The electrochemical parameters $\left(E_{p}, i_{p}, F W H M\right.$ and $\left.\Gamma_{S G}\right)$ extracted from $G G$ function peak fitting agree with those obtained in reference 8 via the Biologic EC-Lab Software, although with slight differences (Figures 4B, 4C and 4D) and the surface coverage dependence of $E_{p}$, FWHM and $i_{p}$ provides direct estimations of interaction parameters $G$ and $S$. We can notice that 3 or 4 unknown parameters peak fitting produced very similar results, although the surface coverages from 4 parameters seem undervalued.

So, what is better for GG function peak fitting of experimental data? It is a GG function with 3 unknown parameters because the variations of $c$ and $b$ with surface coverage from 3 or 4 parameters peak fitting (Figures $4 \mathrm{E}$ and $4 \mathrm{~F}$ ) display a greater dispersion of estimated $\mathrm{c}$ values in the case of 4 unknown parameters.

\section{Conclusion}

We propose a versatile function to fit adsorption voltammetric peak in order to extract the characteristic parameters as the full width at half maximum, the peak potential, the peak current and the surface coverage. This work suggests to fit adsorption voltammetric peak with a 3 parameters GG function in order to finely estimate electrochemical parameters. It should be borne in mind that such calculations require experimental data with the respect of drastic experimental conditions (pure solvent, supporting electrolyte and compounds, substrate with very low roughness, ohmic drop compensation ...). 
Finally, this approach is dedicated to SAMs but it should also apply to a few electroactive layers.

\section{Acknowledgments}

All calculations were performed with SigmaPlot ${ }^{\mathrm{TM}} 12.5$.

The authors thank Flavy Alévêque for her critical reading of the manuscript.

\section{References}

[1] J.C. Love, L.A. Estroff, J.K. Kriebel, R.G. Nuzzo, G.M. Whitesides, Self-assembled monolayers of thiolates on metals as a form of nanotechnology, Chemical Reviews, 105 (2005) 1103-1169.

[2] A.L. Eckermann, D.J. Feld, J.A. Shaw, T.J. Meade, Electrochemistry of redox-active self-assembled monolayers, Coordination Chemistry Reviews, 254 (2010) 1769-1802.

[3] W. Huang, T.L.E. Henderson, A.M. Bond, K.B. Oldham, CURVE-FITTING TO RESOLVE OVERLAPPING VOLTAMMETRIC PEAKS - MODEL AND EXAMPLES, Analytica Chimica Acta, 304 (1995) 1-15.

[4] M. Palys, T. Korba, M. Bos, W.E. Vanderlinden, THE SEPARATION OF OVERLAPPING PEAKS IN CYCLIC VOLTAMMETRY BY MEANS OF SEMI-DIFFERENTIAL TRANSFORMATION, Talanta, 38 (1991) 723-733.

[5] L.Y.S. Lee, R.B. Lennox, Electrochemical desorption of $n$-alkylthiol SAMs on polycrystalline gold: Studies using a ferrocenylalkylthiol probe, Langmuir, 23 (2007) 292-296.

[6] L.Y.S. Lee, T.C. Sutherland, S. Rucareanu, R.B. Lennox, Ferrocenylalkylthiolates as a probe of heterogeneity in binary self-assembled monolayers on gold, Langmuir, 22 (2006) 4438-4444.

[7] H.H. Tian, Y. Dai, H.B. Shao, H.Z. Yu, Modulated Intermolecular Interactions in Ferrocenylalkanethiolate Self-Assembled Monolayers on Gold, Journal of Physical Chemistry C, 117 (2013) 1006-1012.

[8] O. Aleveque, P.Y. Blanchard, T. Breton, M. Dias, C. Gautier, E. Levillain, F. Seladji, Nitroxyl radical selfassembled monolayers on gold: Experimental data vs. Laviron's interaction model, Electrochemistry Communications, 11 (2009) 1776-1780.

[9] O. Aleveque, P.Y. Blanchard, C. Gautier, M. Dias, T. Breton, E. Levillain, Electroactive self-assembled monolayers: Laviron's interaction model extended to non-random distribution of redox centers, Electrochemistry Communications, 12 (2010) 1462-1466.

[10] E. Laviron, Surface linear potential sweep voltammetry: Equation of the peaks for a reversible reaction when interactions between the adsorbed molecules are taken into account, Journal of Electroanalytical Chemistry and Interfacial Electrochemistry, 52 (1974) 395-402.

[11] E. Laviron, General expression of the linear potential sweep voltammogram in the case of diffusionless electrochemical systems, Journal of Electroanalytical Chemistry and Interfacial Electrochemistry, 101 (1979) 19-28.

[12] E. Laviron, L. Roullier, General expression of the linear potential sweep voltammogram for a surface redox reaction with interactions between the adsorbed molecules: Applications to modified electrodes, Journal of Electroanalytical Chemistry and Interfacial Electrochemistry, 115 (1980) 65-74.

[13] P.Y. Blanchard, S. Boisard, M. Dias, T. Breton, C. Gautier, E. Levillain, Electrochemical Transduction on Self-Assembled Monolayers: Are Covalent Links Essential?, Langmuir, 28 (2012) 12067-12070.

[14] O. Aleveque, L. Sanguinet, E. Levillain, Spectroelectrochemistry on electroactive self-assembled monolayers: cyclic voltammetry coupled to spectrophotometry, Electrochemistry Communications, 10.1016/j.elecom.2014.12.014.

[15] P.Y. Blanchard, O. Aleveque, S. Boisard, C. Gautier, A. El-Ghayoury, F. Le Derf, T. Breton, E. Levillain, Intermolecular interactions in self-assembled monolayers of tetrathiafulvalene derivatives, Physical Chemistry Chemical Physics, 13 (2011) 2118-2120. 


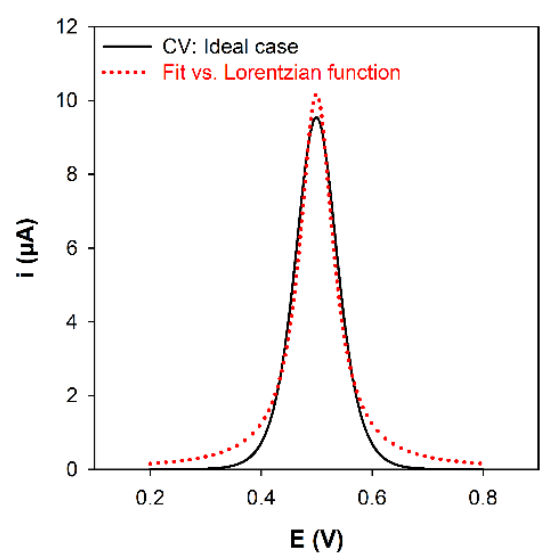

(A)

$f(E)=\frac{a}{\pi b \cdot\left[1+\left(\frac{E-E_{0}}{b}\right)^{2}\right]}$ with $\left\{\begin{array}{l}E_{0} \\ F W H M=2 . b \\ i=\frac{a}{\pi b} \\ \Gamma_{S G}=\frac{a}{n F S v}\end{array}\right.$

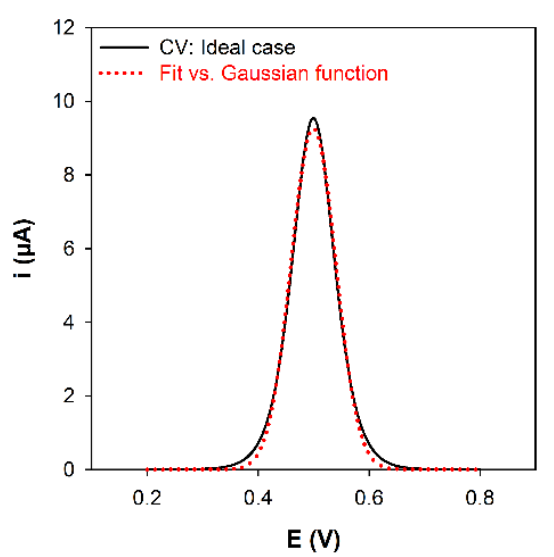

(B)

$f(E)=\frac{a}{b \cdot \sqrt{\pi}} \mathrm{e}^{-\left(\frac{\left|E-E_{0}\right|}{b}\right)^{2}}$ with $\left\{\begin{array}{l}E_{0} \\ F W H M=2 \cdot b \cdot \sqrt{\ln (2)} \\ i=\frac{a}{b \cdot \sqrt{2 \pi}} \\ \Gamma_{S G}=\frac{a}{n F S v}\end{array}\right.$

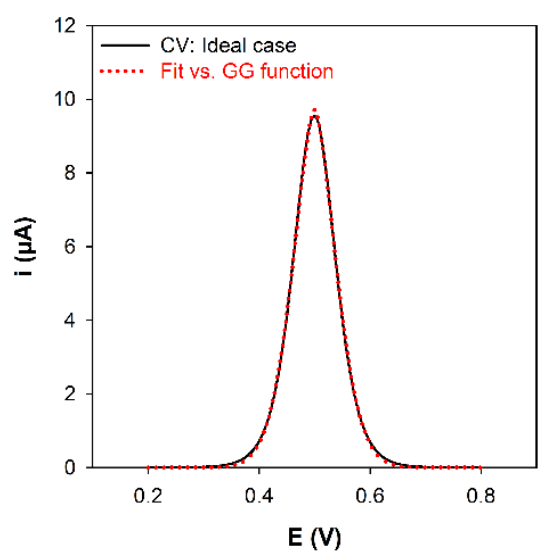

(C)

$f(E)=\frac{a \cdot c}{2 \cdot b \cdot \Gamma(1 / c)} \mathrm{e}^{-\left(\frac{\left|E-E_{0}\right|}{b}\right)^{c}}$ with $\left\{\begin{array}{l}E_{0} \\ F W H M=2 \cdot b \cdot[\ln (2)]^{\frac{1}{c}} \\ i=\frac{a \cdot c}{2 \cdot b \cdot \Gamma(1 / c)} \\ \Gamma_{S G}=\frac{a}{n F S v}\end{array}\right.$

Figure 1. A comparison of peak fitting from an ideal $C V\left(n=1, k=1000 \mathrm{~s}^{-1}, E_{0}=0.500 \mathrm{~V}, T=293 \mathrm{~K}, \mathrm{v}=0.1\right.$ V. $\mathrm{s}^{-1}, \mathrm{~A}=0.2 \mathrm{~cm}^{2}, \mathrm{FWHM}=0.089 \mathrm{~V}$ and and $\Gamma_{\mathrm{SG}}=5.0010^{-10} \mathrm{~mol} . \mathrm{cm}^{-2}$.). (A) Fit vs. Lorentzian function $(3$ unknown parameters): $\mathrm{E}_{0}=0.500 \mathrm{~V}, \mathrm{FWHM}=0.074 \mathrm{~V}$ and $\Gamma_{\mathrm{SG}}=6.1510^{-10} \mathrm{~mol}^{\mathrm{cm}} \mathrm{cm}^{-2}$. (B) Fit vs. a Gaussian function (3 unknown parameters): $E_{0}=0.500 \mathrm{~V}, F W H M=0.095 \mathrm{~V}$ and $\Gamma_{S G}=4.8510^{-10} \mathrm{~mol}_{\mathrm{sm}} \mathrm{cm}^{-2}$. (C) Fit vs. a GG function (4 unknown parameters): $E_{0}=0.500 \mathrm{~V}, F W H M=0.088 \mathrm{~V}$ and $\Gamma_{S G}=4.9510^{-10} \mathrm{~mol}^{-\mathrm{cm}^{-2}}$. Note that $E_{0}=0.500 \mathrm{~V}, \mathrm{FWHM}=0.086 \mathrm{~V}$ and $\Gamma_{\mathrm{SG}}=5.0210^{-10} \mathrm{~mol}_{\mathrm{cm}} \mathrm{cm}^{-2}$ for a $\mathrm{GG}$ function at 3 unknown parameters. 

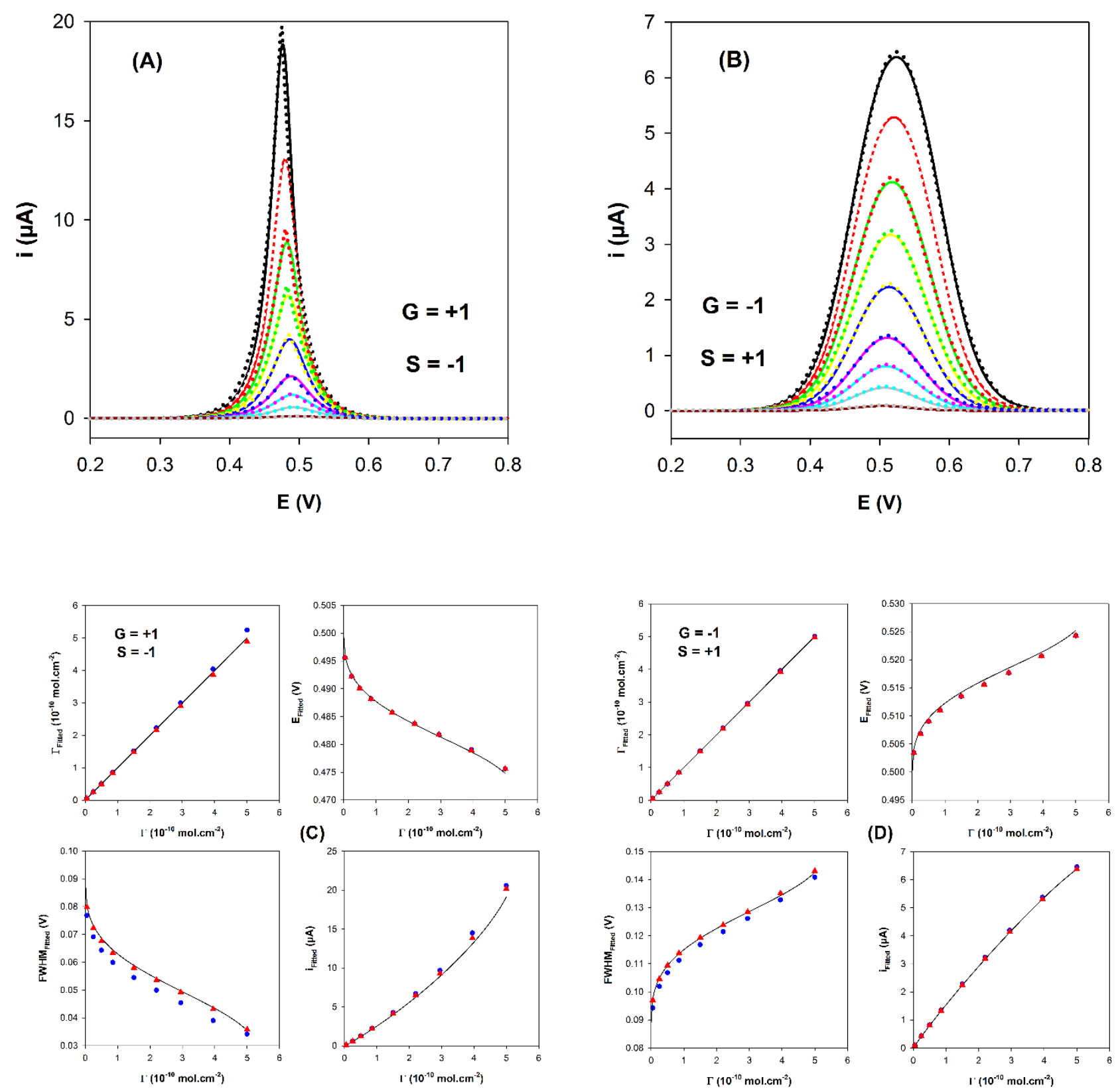

Figure 2. Evaluation of $G G$ function peak fitting on calculated $C V$ s from generalized Laviron model $(n=1, k$ $=1000 \mathrm{~s}^{-1}, \mathrm{E}_{0}=0.500 \mathrm{~V}, \mathrm{~T}=293 \mathrm{~K}, \mathrm{v}=0.1 \mathrm{~V} \cdot \mathrm{s}^{-1}, \mathrm{~A}=0.2 \mathrm{~cm}^{2}$,) in the case of two phase segregations $(\mathrm{G}=1$ and $\mathrm{G}=-1 ; \mathrm{S}=-\mathrm{G}$ ). (A) (line) calculated $\mathrm{CVs}$ for 5.00, 3.95, 2.95, 2.20, 1.50, 0.85, 0.52, 0.25 and $0.0510^{-10}$ mol.cm ${ }^{-2}$ [9] for $G=+1$. (dotted) Fit vs. a GG function (4 unknown parameters). (B) (line) calculated CVs for $5.00,3.95,2.95,2.20,1.50,0.85,0.52,0.25$ and $0.0510^{-10} \mathrm{~mol}_{\mathrm{cm}}{ }^{-2}$ [9] for $\mathrm{G}=-1$. (dotted) Fit vs. a GG function (4 unknown parameters). (C) Fitted surface coverage, fitted apparent potential, fitted FWHM and fitted peak intensity vs. modelled surface coverage from a GG function peak fit in two cases: $3(\bullet)$ and $4(\boldsymbol{\Delta})$ unknown parameters, then compared (line) to generalized Laviron model (see equations 1-3) for $G=+1$. (D) Fitted surface coverage, fitted apparent potential, fitted FWHM and fitted peak intensity vs. modelled surface coverage from a GG function peak fit in two cases: $3(\bullet)$ and $4(\boldsymbol{\Delta})$ unknown parameters, then compared (line) to generalized Laviron model (see equations 1-3) for $\mathrm{G}=-1$. 


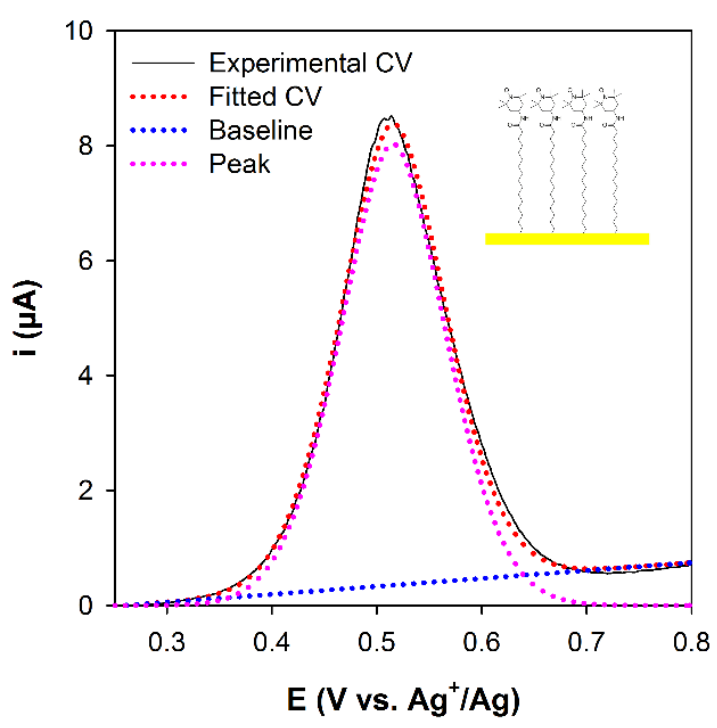

(A)

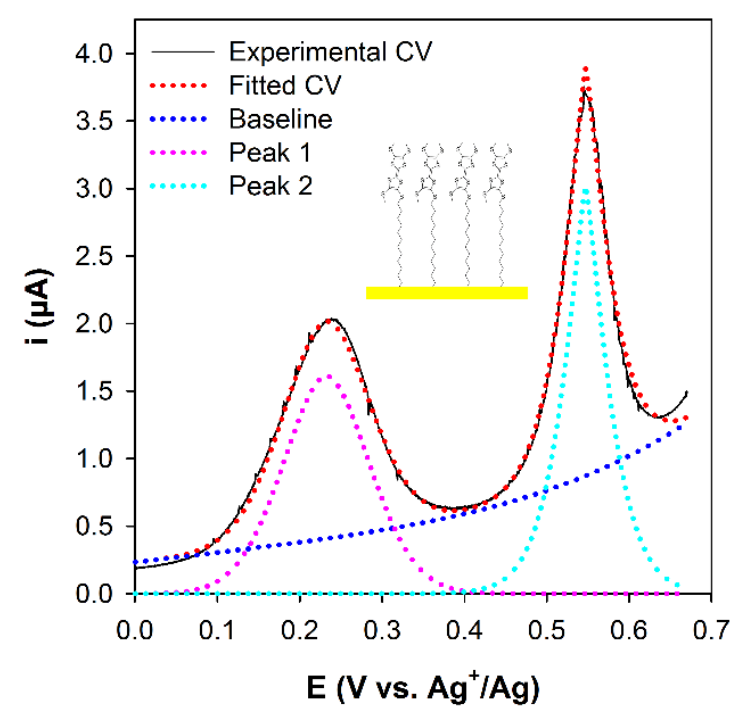

(C)

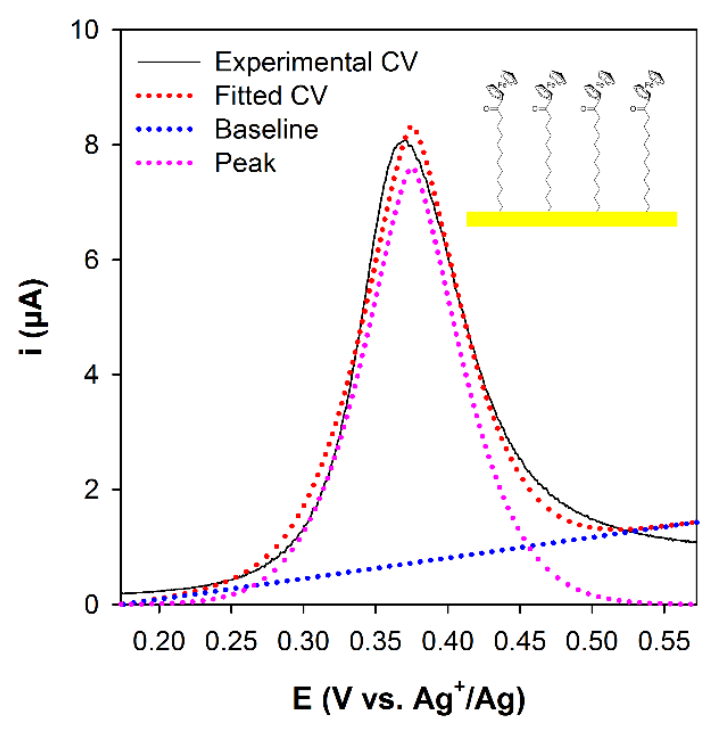

(B)

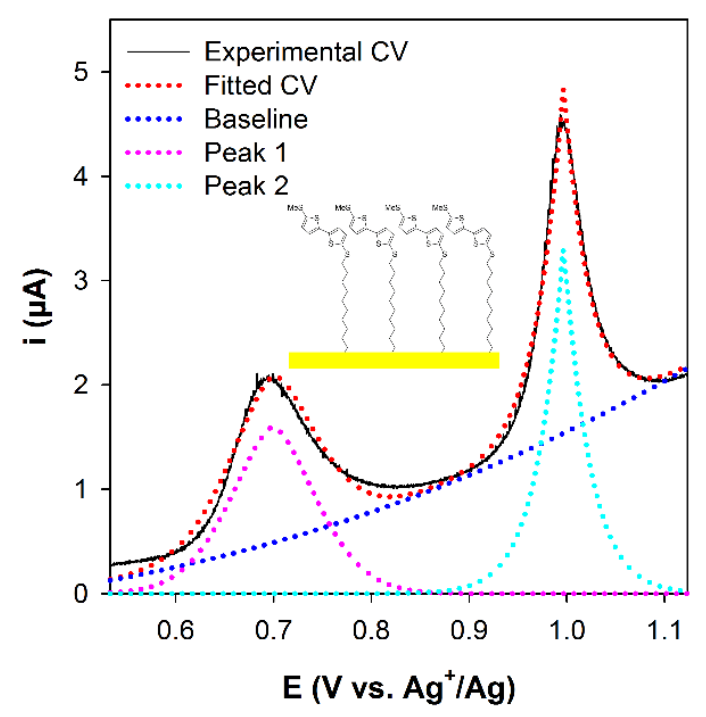

(D)

Figure 3. Evaluation of $G G$ function peak fitting on experimental $C V s$ of different electroactive SAMs. (A) CV of Tempo SAM in $0.1 \mathrm{M} \mathrm{nBu}_{4} \mathrm{NPF}_{6} / \mathrm{CH}_{2} \mathrm{Cl}_{2}$, at $0.1 \mathrm{~V}^{-1}$ and $293 \mathrm{~K}$ [8]. Electrochemical parameters deduced of peak fitting: $E_{0}=0.515 \mathrm{~V}, \mathrm{FWHM}=0.118 \mathrm{~V}, \Gamma_{\mathrm{SG}}=5.3310^{-10} \mathrm{~mol}_{\mathrm{cm}} \mathrm{cm}^{-2}$. (B) CV of Ferrocene SAM in $0.1 \mathrm{M}$ $\mathrm{nBu}_{4} \mathrm{NPF}_{6} / \mathrm{CH}_{3} \mathrm{CN}$, at $0.1 \mathrm{~V} \cdot \mathrm{s}^{-1}$ and $293 \mathrm{~K}$ [13]. Electrochemical parameters deduced of peak fitting: $\mathrm{E}_{0}=$ $0.375 \mathrm{~V}, \mathrm{FWHM}=0.079 \mathrm{~V}, \Gamma_{\mathrm{SG}}=3.6010^{-10} \mathrm{~mol} . \mathrm{cm}^{-2}$. (C) $\mathrm{CV}$ of TTF SAM in $0.1 \mathrm{M} \mathrm{Bu}_{4} \mathrm{NPF}_{6} / \mathrm{CH}_{2} \mathrm{Cl}_{2}$ at 0.1 $\mathrm{V} . \mathrm{s}^{-1}$, at $0.1 \mathrm{~V} . \mathrm{s}^{-1}$ and $293 \mathrm{~K}$ [15]. Electrochemical parameters deduced of two peaks fitting: $\mathrm{E}_{01}=0.232 \mathrm{~V}$, $\mathrm{FWHM}_{1}=0.123 \mathrm{~V}, \mathrm{E}_{02}=0.547 \mathrm{~V}, \mathrm{FWHM}_{2}=0.057 \mathrm{~V}, \Gamma_{\mathrm{SG}}=3.1210^{-10} \mathrm{~mol}_{\mathrm{cm}} \mathrm{cm}^{-2}$. (D) CV of Bithiophene SAM

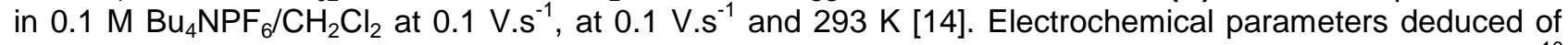
two peaks fitting: $\mathrm{E}_{01}=0.700 \mathrm{~V}, \mathrm{FWHM}_{1}=0.100 \mathrm{~V}, \mathrm{E}_{02}=0.996 \mathrm{~V}, \mathrm{FWHM}_{2}=0.039 \mathrm{~V}, \Gamma_{\mathrm{SG}}=0.9210^{-10}$ mol. $\mathrm{cm}^{-2}$. Note that the two CV peaks were fitted with two GG functions of the same area (i.e. $\left.a_{1}=a_{2}\right)$. 

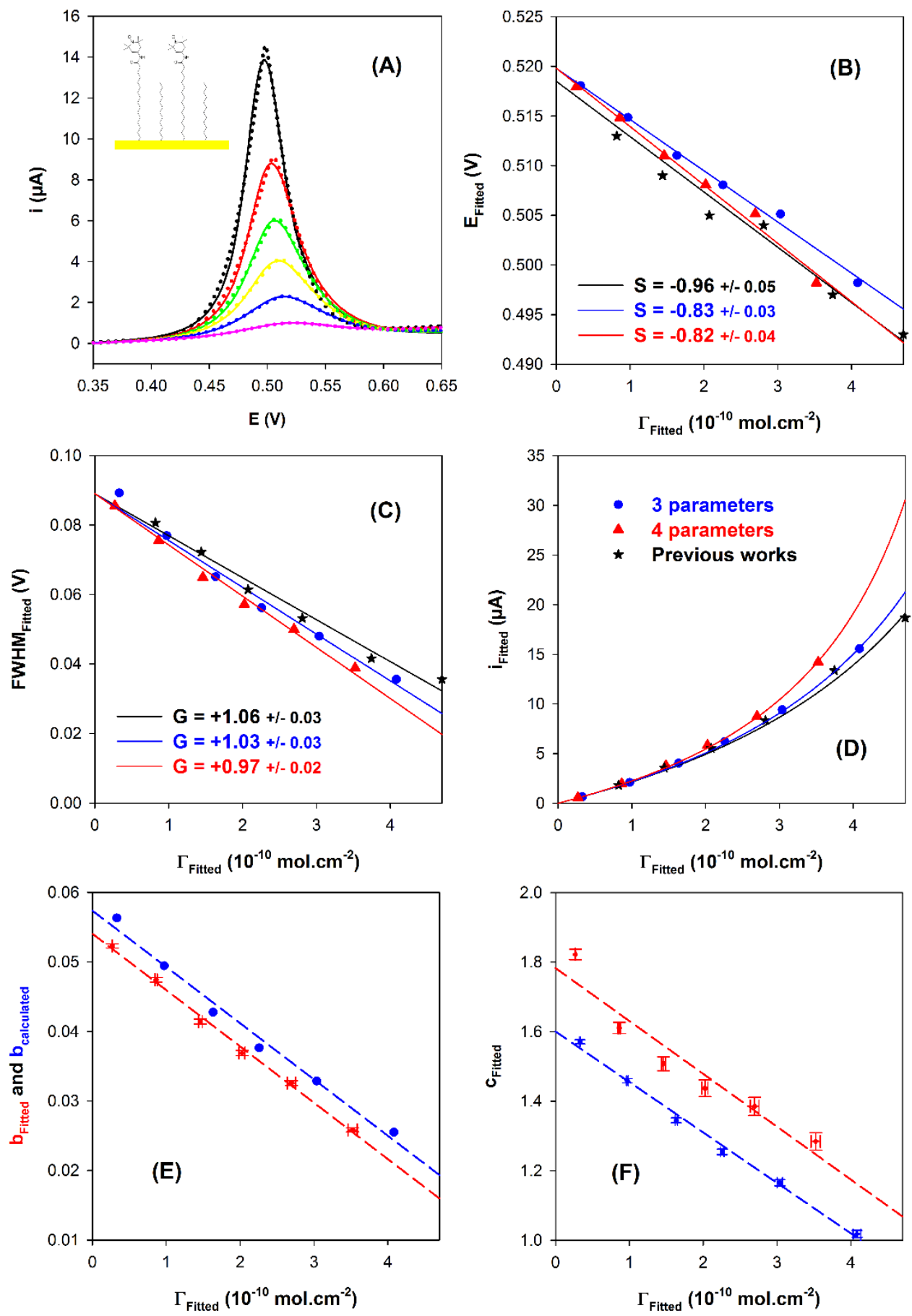

Figure 4. Comparison of GG function peak fitting and experimental CVs of mixed Tempo SAMs, prepared with random distributed electroactive centers on Au substrate (see reference 8). Note that 3 and 4 unknown parameters peak fitting were symbolized by $(\bullet)$ and $(\boldsymbol{\Delta})$, respectively then compared to results (represented by $\star$ ) from reference 8 .

(A) (line) Experimental $\mathrm{CVs}$ of Tempo SAM in $0.1 \mathrm{M} \mathrm{nBu} 4 \mathrm{NPF}_{6} / \mathrm{CH}_{2} \mathrm{Cl}_{2}$, prepared from different Tempo:decanethiol ratios, leading to 4.7 (i.e. $\theta=100 \%$ ), 3.7, 2.8, 2.1, 1.4 and $0.810^{-10} \mathrm{~mol}_{\mathrm{cm}} \mathrm{cm}^{-2}[\mathrm{XX}]$. Note that these surface coverages were deduced by integration of the voltammetric signal. (dotted) Fit vs. a GG function (4 unknown parameters). (B) Fitted apparent potential vs. fitted surface coverage. Estimation of $S$ parameter from equation 1. (C) Fitted FWHM vs. fitted surface coverage. Estimation of G parameter from equation 2. (D) Fitted peak intensity vs. fitted surface coverage. Estimation of $i_{p}$ parameter from equation 3. (E) Fitted b and calculated b (see equation 11) vs. fitted surface coverage. (F) Fitted c vs. fitted surface coverage, displaying a greater dispersion of estimated $\mathrm{c}$ values in the case of 4 unknown parameters peak fitting. 